\title{
IMPLEMENTASI ISLAMIC ENTREPRENEURSHIP \\ DI SMPIT ALIBRAH GRESIK
}

\author{
Maskinah \\ Hamim Farhan \\ Universitas Muhammadiyah Gresik
}

\begin{abstract}
Abstrak: Penelitian ini menggunakan metode deskriptif kualitatif, bertujuan untuk mengetahui bagaimana implementasi Islamic Entrepreneurship di SMP IT Al Ibrah Gresik, dan untuk mengetahui apakah faktor pendukung dan penghambat dalam program tersebut. Target dari penelitian ini adalah kepala sekolah, wakil kepala bagian kurikulum, para guru dan peserta didik. Hasil penelitian menunjukkan bahwa implementasi Islamic Entrepreneurship yang di jalankan di SMP IT AL Ibrah Gresik telah berjalan dengan baik. Hal ini di tunjukkan dengan adanya perubahan karakter Islamic Entrepreneurship dari peserta didik berupa kemandirian, kretifitas, bekerja sama, percaya diri dan komunikatif. Penanaman karakter Islamic Entrepreneurship diintegrasikan ke dalam berbagai program dan mata pelajaran terkait, yaitu pekan entrepreneur atau praktik berwirausaha, muatan lokal seperti program social of tafakur yang berlangsung dengan melibatkan peserta didik ke dalam masyarakat, dan budaya sekolah. Faktor pendukung dari program terkait adalah adanya tim yang solid dari para guru dan semua citivas sekolah dalam menjalankan program yang telah dicanangkan, fasilitas dan kurikulum yang ada, dan antusias peserta didik dalam menjalankannya. Sedangkan faktor penghambatnya adalah perlunya sosialisasi terhadap para wali peserta didik yang belum memahami pentingnya program ini di jalankan karena kekhawatiran terjadi kesulitan bagi peserta didik. Akan tetapi setelah program ini berjalan semua pihak dapat bekerja sama dengan baik.
\end{abstract}

Kata Kunci: entrepreneurship, Islamic Entrepreneurship 


\section{PENDAHULUAN}

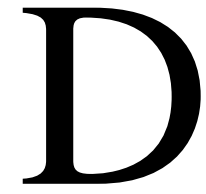

ewasa ini, pengangguran dan kemiskinan yang ada di Indonesia terjadi karena perbandingan antara jumlah lapangan kerja di semua sektor yang meliputi sektor industri, pertanian, pertambangan, transportasi, pariwisata, dan lain-lain tidak sebanding dengan jumlah lulusan yang dihasilkan di segala level pendidikan. Terlebih bagi tenaga kerja yang tidak terdidik, tidak terampil, dan tenaga kerja berpendidikan rendah atau putus sekolah, semakin kecil kemungkinan mereka untuk merebut peluang kerja

Salah satu jalan yang bisa ditempuh untuk bangkit dari keterpurukan adalah kerja keras, kreatif, inovasi rakyat Indonesia lewat kewirausahaan atau entrepreurship. Adalah solusi yang tepat dengan membekali mereka dengan keterampilan berwirausaha agar mereka mampu memperoleh penghasilan dan mencapai kesejahteraan hidup sesuai yang dicita-citakan.

Susilo Bambang Yudhoyono dan Boediono dalam kontes Indonesia, telah secara terbuka menegaskan pentingnya pengembangan pendidikan kewirausahaan pada semua jenjang pendidikan. Boediono bahkan secara spesifik menyebutkan dalam

${ }^{1}$ Dr.R.Lukman Faroni, M.Ag., $\quad$ dkk., PTKI Etrepreneur Gagasan dan Praktik, (Jakarta, Direktorat Pendidikan Tinggi Islam Direktorat pidato acara pemberian penghargaan wirausaha mandiri di Jakarta (Tempo interaktif,22/1/2010) menganjurkan agar pendidikan kewirausahaan dimasukkan dalam kurikulum pengajaran di perguruan tinggi. ${ }^{1}$ Sehingga out put yang di hasilkan akan lebih mandiri dalam menyongsong masa depan dengan adanya bekal pendidikan kewirausahaan.

Indonesia juga merupakan negara dengan populasi mayoritas muslim. Akan tetapi hal ini belum dapat menggambarkan besarnya entrepreneur muslim di negeri ini. Menumbuhkan jiwa wirausaha dari bangsa ini tidaklah semudah membalikkan telapak tangan, atau tercipta dengan instan. Hal ini memerlukan proses yang panjang dan penuh ketekunan. Dalam hal ini pendidikan berperan penting menghasilkan generasi bangsa yang lebih mengarah kepada tumbuh kembangnya para entrepreneur muda.

Salah satu sekolah yang mengambil pelajaran dan praktik tentang Islamic Entrepreneurship ke dalam kurikulum sekolah adalah SMPIT ALIBRAH GRESIK. SMPIT ALIBRAH GRESIK

Berdasarkan hasil wawancara untuk studi pendahuluan, penanaman Islamic Entrepreneurship di SMPIT ALIBRAH GRESIK sudah berjalan cukup baik.

Jenderal Pendidikan Islam kementerian Agama RI, 2016), hlm. 8 
Penanaman nilai-nilai Islamic Entrepreneurship sudah diterapkan baik dalam kurikulum sekolah, pembelajaran di kelas dan kegiatan di luar kelas. Namun dalam pelaksanaannya masih terdapat berbagai kendala seperti : kreativitas peserta didik yang tidak merata, antusias dan dukungan orang tua yang belum optimal maupun usaha-usaha sekolah dalam menggandeng kerja sama lebih luas lagi dengan pihak luar. Sehingga masih perlu pengembangan strategi baik sekolah maupun guru dalam penanaman nilai-nilai Islamic entrepreneurship di sekolah ini.

Dari latar belakang di atas, Peneliti tertarik untuk meneliti lebih lanjut tentang pelaksanaan Islamic Enterpreneurship di sekolah tersebut. Dengan judul skripsi "Implementasi Islamic Entrepreneurship di SMPIT Al Ibrah Gresik"

\section{Rumusan Masalah}

Dari pembatasan permasalahan yang ada, peneliti merumuskan masalah sebagai berikut :

1. Bagaimana implementasi Islamic Entrepreneurship di SMPIT AL IBRAH?

2. Apakah faktor pendukung dan penghambat implementasi Islamic Entrepreneurship di SMPIT AL IBRAH?

\section{Manfaat Penelitian}

Penelitian dilaksanakan dengan harapan memiliki manfaat sebagai berikut:

Secara teoritis, hasil dari penelitian ini diharapkan dapat menambah informasi dan ilmu pengetahuan Islam serta dapat dijadikan sebagai acuan bagi penelitian selanjutnya.

Secara praktis, hasil penelitian ini diharapkan dapat bermanfaat bagi :

a. Bagi kepala sekolah sebagai bahan pertimbangan dalam membuat kebijakan-kebijakan terkait pendidikan Islamic Entrepreneurship di sekolah.

b. Bagi guru sebagai acuan dalam berinovasi dan menjalankan program-program sekolah khususnya tentang karakter entrepreneur peserta didik.

c. Bagi peserta didik sebagai penambahan wawasan tentang kewirausahaan sebagai bekal keterampilan yang berguna di kemudian hari.

d. Bagi masyarakat sebagai bahan pertimbangan dalam memilih karakter dan budaya sekolah. 


\section{KAJIAN PUSTAKA}

\section{Pengertian Entrepreneurship}

Istilah "entreprenuer" berasal dari Bahasa Perancis yaitu entreprende yang berarti petualang, pengambil risiko, kontraktor, pengusaha (orang yang mengusahakan suatu pekerjaan tertentu), dan pencipta yang menjual hasil ciptaannya.(Muhammad Anwar, 2014: 2).

Karakteristik Islamic Entrepreneurship

Entrepreneur dalam pandangan Islam adalah orang yang selalu berpedoman kepada Al Quran dan Al Hadits dalam setiap langkahnya. Nilai-nilai entrepreneurship menurut perspektif Al-Qur'an dan Al Hadits seperti yang ditulis oleh T.Distianto adalah sebagai berikut: ${ }^{2}$

a. Keyakinan dan Tauhid

b. Keteladanan kepada Nabi dan Sahabatnya

c. Kerja Keras

d. Kemandirian Dalam dunia entrepreneur

e. Menjauhi Sifat Malas

f. Kejujuran

${ }^{2}$ T.Distianto, Konsep Pendidikan Islam dan Entrepreneurship,http://digilib.uinsby.ac.id/2000/6/Bab\%2 03.pdf Diakses tanggal 24 Februari 2018 g. Kreativitas

h. Semangat berbagi atau sedekah

i. Silaturahmi

\section{Urgensi Islamic Entrepreneurship} dalam dunia pendidikan

Secara umum, pendidikan agama Islam bertujuan untuk meningkatkan keimanan, pemahaman, penghayatan dan pengamalan peserta didik tentang agama Islam, sehingga menjadi manusia muslim yang beriman dan bertakwa kepada Allah SWT. serta berakhlak mulia dalam kehidupan pribadi, bermasyarakat, berbangsa dan bernegara. ${ }^{3}$

Pendidikan berfungsi sebagai alat untuk mencapai tujuan Islam. Ada hubungan keterkaitan antara tujuan pendidikan Islam dengan entrepreneurship. Entrepreneurship merupakan nilai yang positif dan sangat relevan dengan tujuan pendidikan Islam. Seorang entrepreneur muslim dalam seluruh niat dan aktivitas kehidupannya akan senantiasa berlandaskan prinsip-prinsip ajaran dalam perspektif Al-Qur'an dan Hadits.

\section{Kerangka Berpikir}

Implementasi nilai-nilai Islamic Entrepreneurship menjadi urgen dalam dunia

\footnotetext{
${ }^{3}$ Muhaimin, Paradigma Pendidikan Islam, (Bandung, Remaja Rosda Karya, 2004), hlm 78
} 
pendidikan dewasa ini. Pendidikan sebagai alat pencapaian tujuan penerapan keislaman. Pendidikan Islamic Entrepreneurship akan melahirkan pribadi-pribadi yang bertauhid kuat, mandiri, kerja keras, jujur, kreatif, inovatif, percaya diri, suka berbagi atau bersedekah dan bersilaturahmi.

Sekolah dapat mengupayakan berbagai program dan strategi terkait nilai-nilai Islamic entrepreneurship dengan mengintegrasikannya ke dalam kurikulum sekolah, kegiatan pembelajaran, ekstrakurikuler sekolah, muatan lokal dan budaya atau kultur sekolah. Sehingga diharapkan dapat menumbuhkan sikap yang mencerminkan entrepreneur muslim sejati dalam kehidupan peserta didik.

\section{METODOLOGI PENELITIAN}

\section{Jenis dan Pendekatan Penelitian}

Penelitian ini menggunakan jenis penelitian lapangan (field research). Jenis penelitian lapangan adalah penelitian yang dilakukan di lapangan atau dalam masyarakat. Hal ini berarti data yang di ambil berasal dari lapangan atau masyarakat. ${ }^{4}$

\footnotetext{
${ }^{4}$ Jusuf Soewadji, Pengantar Metodologi Penelitian, (Jakarta: Mitra Wacana Media, 2012), hlm. 21
}

\section{Waktu dan Tempat Penelitian}

Penelitian ini dilaksanakan di SMPIT ALIBRAH GRESIK di Jl.Kng Brotonegoro Timur Gresik Kota Baru Manyar Gresik Telp. 3955088. Adapun waktu pelaksanaan direncanakan mulai bulan Oktober sampai dengan bulan Januari 2018.

\section{Sumber Data}

Sumber data yang dimaksud dalam penelitian ini adalah subyek dari mana data diperoleh. Peneliti berinteraksi langsung dengan informan yaitu : Kepala SMP IT Al Ibrah Gresik, guru-guru terkait dan para siswa. Peneliti juga mendapat sumber data yang tidak langsung dari informan, tetapi melalui penelusuran berupa data siswa, profil sekolah, visi misi sekolah, dokumen, serta unsur penunjang lainnya.

\section{Teknik Analisis Data}

Model yang digunakan teknis analisis data dalam penelitian kualitatif adalah model analisis dan mengalir (flow model).Terdiri dari pengumpulan data, reduksi data, penyajian data, dan penarikan kesimpulan. 


\section{HASIL PENELITIAN}

\section{Implementasi Islamic Entrepre- neurship di SMP IT Al Ibrah}

Gambaran umum implementasi Islamic Entrepreneurship di SMP IT Al Ibrah Gresik dihasilkan dari wawancara secara mendalam dengan pihak-pihak terkait di sekolah, melakukan observasi dan dokumentasi. Sehingga mendapatkan informasi yang benar-benar sesuai di lapangan dan sesuai dengan tujuan diadakannya penelitian ini.

Islamic Entrepreneurship adalah salah satu program yang di ambil sekolah yang membedakan SMP IT Al Ibrah dengan sekolah lainnya di Gresik. Program ini masuk ke dalam kurikulum muatan lokal. Latar belakang diadakannya program ini adalah seperti yang dituturkan oleh Kepala SMP IT Al Ibrah Gresik, Bapak Nasyiruddi, Lc. bahwa $80 \%$ peserta didik Kami adalah berasal dari golongan mampu secara materi, dan $60 \%$ adalah berwirausaha. Adanya ketidakpastian masa yang akan datang dan beratnya persaingan hidup di masa nanti memacu Kami untuk ikut mempersiapkan generasi yang siap hidup di masa yang akan datang terutama menyangkut ibadah, skil dan kemandirian. Yaitu dengan adanya program Islamic Entrepreneurship. Tujuan di adakannya program ini adalah agar peserta didik memiliki nilai-nilai atau karakter Islamic entrepreneur, percaya diri, bertanggung jawab, produktif dan inovatif serta terutama mandiri.

Ada beberapa strategi yang dijalankan sekolah dalam implementasi Islamic Entrepreneurship. yaitu ;

a. Mengintegrasikan ke dalam mata pelajaran terkait

Mengintegrasikan nilai-nilai Islamic Entrepreneurship ke dalam mata pelajaran terkait artinya nilai-nilai Islamic Entrepreneurship disisipkan dalam bab- bab dari mata pelajaran terkait, Sebagaimana yang dijelaskan oleh ustazah Nur Ainiyah bahwa sekolah belum mengharuskan semua mata pelajaran mengaitkan dengan entrepreneurship, akan tetapi sekolah membentuk kelompok apabila ada tema yang bersesuaian dengan mata pelajaran lain. Contohnya seperti di bawah ini.

Tabel Kesesuaian Sub Tema Dalam Mata pelajaran

\begin{tabular}{|c|c|c|c|}
\hline No & Mata Pelajaran & Tema & Kelas \\
\hline 1 & Pendidikan Agama Islam & Bab Jual Beli & 8 \\
\hline 2 & Matematika & Hitungan & 8 \\
\hline 3 & IPS & Bab Pasar & 8 \\
\hline
\end{tabular}




\begin{tabular}{|c|c|c|c|}
\hline 4 & SBK & $\begin{array}{c}\text { Membuat barang berguna dari bahan } \\
\text { bekas }\end{array}$ & 8 \\
\hline
\end{tabular}

b. Mengacu kepada kurikulum muatan lokal

Mengacu kepada kurikulum muatan lokal artinya sekolah memiliki programprogram dalam melaksanakan penanaman Islamic entrepreneurship, seperti adanya pekan entrepreneur, Tahfidz, keputrian, teknik komputer dan program sosial of tafakur.

Program pekan entrepreneur sudah berjalan cukup lancar dan mendapat sambutan serta dukungan dari seluruh citivas sekolah. Begitu juga program-program lainnya. Diharapkan melalui berbagai program tersebut akan muncul karakter Islami entrepreneurship dari diri peserta didik. Terutama karakter kemandirian, bertanggung jawab, percaya diri, kreatif dan inovatif.

Sedangkan dalam program sosial of tafakur Peserta didik dalam program ini dilibatkan untuk terjun ke masyarakat. Mencoba hidup di masyarakat dengan berbagai keadaan, berbagai kegiatan dan usaha. Dengan kegiatan ini diharapkan peserta didik bertambah ilmu, mengaplikasikan karakter-karakter muslim entrepreneur dalam kehidupan nyata seperti :mandiri, bertanggung jawab, bekerja sama, saling menghargai, kreatif dan inovatif.

Kegiatan yang dilakukan dalam program sosial of tafakur di antaranya yaitu : Menjual pakaian layak pakai untuk dana sosial. Belajar menjual barang tidak terpakai agar bisa bermanfaat. Peserta didik di harapkan mampu menghargai barang yang ada sekaligus dapat membantu dana sosial. Kemudian melihat dari dekat profesi peternak sapi. Peserta didik sangat bersemangat melakukan kegiatan di peternakan sapi. Di harapkan peserta didik mampu menghargai berbagai profesi, membuka wawasan berwirausaha, dan giat bekerja.

\section{c. Praktik berwirausaha}

Praktik berwirausaha diadakan melalui program pekan entrepreneur. Sekolah memberikan modal Rp. 80.000,- sebagai modal. Kemudian peserta didik secara berkelompok mengelola uang tersebut untuk membeli alat dan bahan berjualan. Mereka juga ditugaskan untuk menghitung modal yang dikeluarkan dan laba penjualan. Peserta didik menjadi lebih percaya diri dan bisa bekerja sama dalam tim serta bertanggung jawab. 
d. budaya sekolah,

Budaya sekolah sangat mendukung terlaksananya program Islamic Entrepreneurship. Sekolah senantiasa melibatkan seluruh civitas sekolah, peserta didik bahkan wali santri untuk menyukseskan program ini, terutama apabila ada even-even tertentu seperti yang dikemukakan oleh Bapak kepala sekolah, bahwa Budaya sekolah ikut mendukung program ini. Misalnya apabila ada even-even tertentu seperti milad Al Ibrah maka seluruh warga sekolah dilibatkan langsung untuk mengadakan bazar, kegiatan amal dan pameran. Pengumpulan barang bekas dari peserta didik yang masih layak pakai, kemudian dijual lagi dan hasilnya dikumpulkan untuk di sumbangkan kepada yang membutuhkan. Begitu pun kalau ada pameran, hasil karya peserta didik, bagi wali santri yang berkenan membeli hasilnya juga akan kita sumbangkan kepada yang membutuhkan.

Pengintegrasian nilai-nilai Islamic Entrepreneurship juga dapat juga dilihat berdasarkan :

a. Pembelajaran di kelas

Proses belajar mengajar di kelas tidak semata menggunakan metode ceramah atau cerita, tetapi menggunakan model problem based introduction (PBI). Yakni metode yang menggunakan pendekatan pembelajaran siswa pada masalah kehidupan nyata dan dikembangkan untuk membantu siswa mengembangkan kemampuan berpikir, pemecahan masalah, dan keterampilan intelektual. Belajar berbagai peran melalui pengalaman belajar dalam kehidupan nyata.

b. Karakter peserta didik

Melalui berbagai program yang dicanangkan, peserta didik telah dapat mencerminkan perilaku muslim entrepreneur seperti mandiri, bertanggung jawab, percaya diri, produktif dan inovatif.

\section{c. Peran guru}

Peran guru dalam hal ini sangat dibutuhkan terutama dalam menyusun berbagai program dan terlaksananya program. Kerja sama tim guru yang solid sangat dominan sehingga implementasi Islami entrepreneurship dapat terus berjalan dan berkembang dengan melakukan perencanaan sekaligus mengevaluasi di setiap akhir kegiatan program guna peningkatan selanjutnya.

Faktor Pendukung dan Faktor Penghambat Implementasi Islamic Entrepreneurship di SMP IT Al Ibrah Gresik

Faktor pendukung terlaksananya program Islamic Entrepreneurship di SMP IT Al Ibrah Gresik berdasarkan data dari observasi, wawancara dan dokumentasi adalah adanya sarana dan prasarana yang memadai, program-program entrepreneur, 
kepala sekolah dan guru-guru yang aktif mendukung dan peserta didik yang antusias dalam menjalankan program. Sekolah juga memiliki satu tim khusus atau kelompok kerja dari guru-guru yang di kepalai oleh seorang ketua pokjar.

Antusias peserta didik dalam menjalankan program Islamic Entrepreneurship adalah salah satu faktor yang sangat mendukung tetap terlaksananya program ini, Terlaksananya program Islamic Entrepreneurship ini juga tidak terlepas dari kendalakendala seperti yang dituturkan oleh kepala sekolah bahwa diperlukan sedikit waktu pada awalnya untuk mensosialisasikan kepada orang tua siswa dan masyarakat. Karena orang tua biasanya akan bertanya apabila ada insiden-insiden kecil yang terjadi ketika proses memasak misalnya kecipratan minyak, atau kuah panas, terkena pisau dan sebagainya. Seiring berjalannya waktu wali santri sudah terbiasa dan bahkan mendukung program.

\section{SIMPULAN}

Berdasarkan hasil penelitian kualitatif tentang Implementasi Islamic Entrepreneurship di SMP IT Al Ibrah Gresik, dengan menggunakan metode observasi, wawancara dan dokumentasi, peneliti dapat menarik beberapa kesimpulan bahwa Implementasi Islamic Entrepreneurship di SMP IT Al
Ibrah Gresik dilaksanakan dengan baik dan terarah.

Strategi yang di gunakan sekolah adalah dengan memasukkan Islamic Entrepreneurship ke dalam program sekolah. Program tersebut adalah pekan entrepreneur dan social of tafakur. Dalam program pekan entrepreneur peserta didik belajar untuk merencanakan, membuat dan menjual produk Sekolah memberikan modal awal sebesar Rp.80.000 rupiah kepada tiap-tiap kelompok. Dalam program ini peserta didik belajar untuk bekerja sama, mandiri, inovatif dan percaya diri. Sedangkan program social of tafakur peserta didik belajar terjun ke masyarakat. Melihat langsung berbagai profesi dan usaha yang dilakukan masyarakat seperti berdagang, rumah produksi kerudung, dan peternakan sapi. Selama 5 hari peserta didik belajar menjalankan Islamic entrepreneur dengan melibatkan masyarakat setempat. Mereka juga mengadakan bakti sosial dengan menjual sembako murah dan menjual pakaian masih layak pakai. Dana yang terkumpul digunakan untuk diberikan kepada masyarakat yang membutuhkan. Secara keseluruhan program terkait di laksanakan dengan lancar.

Terdapat faktor pendukung terlaksananya program Islamic Entrepreneurship ini dengan baik, seperti sarana dan prasarana yang memadai, kurikulum muatan lokal, kerja sama para guru, antusias peserta didik 
dalam mengikuti berbagai kegiatan yang mendukung, hingga dukungan yang positif dari wali santri dan pihak-pihak luar tang terkait. Peserta didik dapat mengikuti program Islamic Entrepreneurship dengan semangat dan senang. Mereka juga sudah dapat merasakan manfaat mengikuti program ini, yaitu : lebih percaya diri, bertanggung jawab, bisa bekerja sama dengan tim dan mandiri.

Beberapa kendala juga dialami dalam implementasi Islamic Entrepreneurship di sekolah ini. Baik oleh sekolah, guru dan peserta didik, di antaranya : perlunya kreativitas guru dan wawasan yang memadai, aktifnya bimbingan terhadap peserta didik, peralatan dan bahan, manajemen waktu dan peningkatan skill peserta didik. Namun terhadap berbagai kendala tersebut tidak menyurutkan semangat sekolah untuk terus meningkatkan mutu pelaksanaan program Islamic Entrepreneurship.

\section{Kritik dan Saran}

1. Sekolah hendaknya menciptakan lebih beragam lagi keterampilan yang bisa di berikan kepada peserta didik seperti: budi daya, memanfaatkan lahan yang ada dan praktik memasak.

2. Untuk tim guru yang mengampu mata pelajaran yang terkait dengan Islami entrepreneurship hendaknya lebih meningkatkan kerja sama, komunikasi dan ide yang lebih kreatif dan inovatif.

3. Peserta didik hendaknya lebih meningkatkan semangat untuk berkarya dan lebih kreatif lagi.

\section{DAFTAR PUSTAKA}

Dr.R.Faroni Lukman, M.Ag., dkk., 2016. PTKI Etrepreneur Gagasan dan Praktik, Jakarta, Direktorat Pendidikan Tinggi Islam Direktorat Jenderal Pendidikan Islam kementerian Agama RI.

Herdiansyah Haris, 2011. Metodologi Penelitian Kualitatif untuk Ilmu-Ilmu Sosial, Jakarta, Salemba Humanika.

Muhaimin, 2004. Paradigma Pendidikan Islam, Bandung, Remaja Rosda Karya.

Nasib Muhammad Ar Rifai, 2007. Kemudahan dari Allah Ringkasan tafsir Ibnu Katsir, Jakarta, Gema Insani.

Soewadji Jusuf, 2012. Pengantar Metodologi Penelitian, Jakarta, Mitra wacana Media.

Syed Nasir Muhammad, 2005. Islam Konsepsi dan Sejarahnya, Bandung, PT. Remaja Rosda Karya.

Prof. Dr. Winardi J., SE., 2008. Entrepreneur dan Entrepreneurship, Jakarta, Kencana Prenada Media Group. 
Suryana, 2013. Kewirausahaan Kiat dan Proses Menuju Sukses, Jakarta, Salemba Empat.

Saiman Leonardus, 2014. Kewirausahaan Teori, Praktik, dan Kasus-kasus, Jakarta, Salemba Empat.

Sri Wigati M.E.I., Kewirausahaan Islam \{Aplikasi dan Teori),http://digilib. uinsby.ac.id/20257/1/kewirausahaan\%2 OIslam.pdf.,diakses tanggal 24 Februari 2018

Santosa Ippho, Hanya 2 Menit Anda Bisa Tahu Potensi Rezeki Anda, Jakarta, PT Elex Media Komputindo Kelompok Gramedia, 2012

T.Distianto, Konsep Pendidikan Islam dan Entrepreneurship,http://digilib.uinsby.a c.id/2000/6/Bab\%203.pdf Diakses tanggal 24 Februari 2018 http://download.portalgaruda.org/article.ph $\mathrm{p}$ ?article $=507322 \& \mathrm{val}=10379 \&$ title $=P$ ENDIDIKAN\%20ISLAM\%20DAN\%2 OENTERPRENEURSHIP, Diakses tgl 02-November-2018

S. Setyowati, Jenis dan Desain Penelitian, http ://eprints.ums.ac.id/12891/6/BABIII-bner.pdf. Diakses tanggal 15Januari-2019

http//www.Bps.go.id/pressrelease/2017/06/ 1377/Agustus-2017-tingkat penganggu ran-terbuka-tpt, Diakses tanggal 08Februari-2018 http://smpitalibrahgresik.blogspot.co.id/ Diakses tanggal 05-November-2018 
Jurnal TAMADDUN - FAI UMG. Vol. XXI. No.1 / Januari 2020 